\title{
Revealing the Black Box of Shifting from Electronic Commerce to Mobile Commerce: The Case of Jordan
}

\section{Ahmad Samed Al-Adwan', Mohammad Alrousan², Anas Al-Soud ${ }^{3}$ and Hussein Al- Yaseen $^{4}$}

${ }^{1}$ Al Ahliyya Amman University, Business School, Department of Information Systems, Amman, Jordan, a.adwan@ammanu.edu.jo

${ }^{2}$ Al Ahliyya Amman university, Business School, Department of Electronic business \& Commerce, Amman, Jordan, m.alrousan@ammanu.edu.jo

${ }^{3}$ Al Ahliyya Amman university, Business School, Department of Electronic business \& Commerce, Amman, Jordan, a.alsoud@ammanu.edu.jo

${ }^{4}$ Al Ahliyya Amman University, Business School, Department of Information Systems, Amman, Jordan, hyaseen@ammanu.edu.jo

Received 5 May 2017; received in revised form 30 December 2017; accepted 16 January 2018

\begin{abstract}
Mobile computing and the wireless web are likely to become the next major business models following the era of electronic commerce. In particular, rapid growth and the advancement in mobile technologies indicate that mobile commerce (m-commerce) will be the dominant business model in the future. In developing countries, services in mobile commerce are in a phase of rapid growth, yet the relevant research is limited. Thus, to increase the adoption of m-commerce among consumers in developing countries such as Jordan, the current study develops a model of consumers' intentions to transfer from traditional (internet-based) e-commerce to $\mathrm{m}$ commerce. The proposed model was empirically validated using a total of 451 paper-based questionnaires that were collected from undergraduate students at three private Jordanian universities. The reliability and validity of the structural model were evaluated by performing exploratory and confirmatory factor analyses, while the structural model was assessed by employing the structural equation modelling approach. The findings demonstrate that consumers' intention to shift from traditional e-commerce to m-commerce can be explained by factors related to perceived differences in technology and value. The research model offers useful and insightful information to help practitioners and developers focus their efforts in designing and delivering effective $\mathrm{m}$ commerce applications.
\end{abstract}

Keywords: M-commerce, Risk perception, E-commerce, Perceived personalisation, Mobile shopping, Online shopping. 


\section{Introduction}

Despite the fact that electronic commerce (e-commerce) has made a radical shift in how businesses perform their processes and activities, the emergence of $m$-commerce has further expanded the boundaries of the revolution in virtual commerce [48]. E-commerce has become increasingly important in recent years, and can be defined as the use of a computer-mediated network, mainly the internet, to conduct transactions of buying and selling, as well as the exchange of information and products [60]. The term electronic used in the specific context of e-commerce indicates an anytime access to all business processes. Such access requires stationary computer networks with wired infrastructure, thus services are not entirely independent of the geographical location of users [58]. The term commerce refers fundamentally to the processes of the sale and purchase of goods and services between business and consumer segments, and to all direct activities associated to such transactions. These activities can be business-to-business (B2B), consumer-to-consumer (C2C) and business-to-consumer (B2C) oriented. However, development strategies for e-commerce applications are witnessing remarkable progress due to the continuous and phenomenal growth of ecommerce [28]. In particular, the global trend focuses on the utilisation of mobile and wireless technologies as the foundation of advancing e-commerce applications. According to [66], the emergence of advanced mobile and wireless technologies holds significant benefits for e-commerce applications and activities, specifically e-commerce applications that are now available in a mobile environment and accessible through mobile devices.

The impressive advancements in mobile and wireless services, and the significant availability of mobile devices, which in many countries is higher than the availability of computers, leads to concepts in innovative mobile services, commonly known as Mobile Commerce (m-commerce) [27]. The steady growth in m-commerce (also known as mobile e-commerce, wireless e-commerce) can be traced back primarily to technological innovations in wireless networks and mobile communication. For instance, high-speed and advanced data transmission technologies, and welldeveloped mobile devices, equipped with improved computing power, adequate data storage capacity, and an enhanced user-interface, create new opportunities and applications for businesses and consumers, which build new business models for mobile operators [58]. Furthermore, other factors such as the increasing penetration of mobile devices, especially mobile phones, into people's daily lives, and the universal trend towards economic globalisation, are considered among the major driving factors behind the need for mobility [28].

The term m-commerce has evolved from the mobile nature of the wireless environment that supports mobile electronic transactions [13]. M-commerce has been defined in different ways throughout the literature. Some scholars conceive m-commerce as any business transaction, such as buying and selling, that is carried out over a mobile telecommunications network and includes a monetary value [28]. However, some m-commerce transactions are conducted without requiring monetary transfer, and such transactions can also be performed through other means of wireless channels [49]. Moreover, not all commercial transaction processes are required to be conducted solely electronically. Some transactions are essentially initiated and accomplished electronically, whereas other transactions are launched electronically but completed off-line. As a consequence, [57] p.42 defines m-commerce broadly as all activities related to a (potential) commercial transaction conducted through communications networks that interface with wireless (or mobile) devices.

Mobile devices are used to connect to mobile services such as smartphones, personal digital assistants (PADs) and handheld computers (i.e. palmtop and tablet computers). These activities include exchanging services, goods and information for money or other information, and are conducted between businesses, individuals, governments, households and private or public organisations. Transactions in m-commerce are conducted over mobile networks, whereas in e-commerce transactions are performed through wired connections. According to [3], the dramatic evolution of $\mathrm{m}$-commerce has announced major changes in different fields and industries (i.e. economy, finance, service, trade). In m-commerce, consumers can conduct various business activates remotely through their mobile devices, which in turn save costs, time and effort. Consequently, the number of organisations that are engaging in $\mathrm{m}$-commerce is increasing significantly, which means that there will be wide types of business operations and services in low costs.

\section{Significance of the Study}

Despite the significant benefits of $\mathrm{m}$-commerce, consumers' transforming behaviour from e-commerce to m-commerce is subject to several issues and challenges. According to [57], from a business perspective, several managerial and technological concerns are raised when it comes to the adoption of $\mathrm{m}$-commerce and its applications, as well as issues related to individuals, governments and other parties. These issues are related to $\mathrm{m}$-commerce technology such as communication infrastructure, design of mobile device software and mobile devices' usability and interface. Establishing new wireless infrastructure requires high cost which many businesses find challenging. Additionally, both businesses and users are concerned about whether the data is secure when transferred over wireless networks. Furthermore, the design of robust mobile applications is viewed a complex task. Developing intra/inter organisational applications that work efficiently with the limitations of mobile devices requires comprehensive analysis, planning, design and implementation. Governments also suffer with legal issues, lack of global standards and laws that govern the public use of mobile devices. 
Therefore, the aim of this study is to construct a theoretical model that explains and explores the influences that stimulate consumers' behavioural intentions to transfer from e-commerce to m-commerce in Jordan. Compared to neighbouring countries, Jordan has a particularly solid ICT infrastructure. Internet services in Jordan are reliable with reasonable speeds serving commercial organizations and citizens [69]. According to official figures released by the Jordanian Telecommunication Regulatory Commission (TRC) (2016), there were 14 million mobile users in the first quarter of 2016, with an impressive penetration rate of $148 \%$. Furthermore, the number of internet users is around 8.1 million with a penetration rate of $84 \%$. Such factors encourage and facilitate the growth of the e-commerce adoption rate in Jordan, although this growth rate remains slow. On the other hand, [45] point out that m-commerce adoption in Jordan is still immature and its diffusion is at a very early stage. In addition, the Jordanian trade sector and consumers are still slow to embrace the use of wireless technology. In fact, the growing numbers of mobile devices and wireless networks does not inevitably mean that the adoption of $\mathrm{m}$-commerce will be an easy process without any impediments. As a consequence, to ensure a successful transformation from traditional e-commerce to m-commerce several factors should be addressed, specifically the driving factors that influence consumers' behavioural intentions to transfer from internet-based e-commerce to m-commerce. Therefore, studies such as the current one are important in overcoming the developmental lag in the adoption of $\mathrm{m}$-commerce in Jordan. This study aims at answering the following question: what factors drive consumers' intention to transfer from internet-based e-commerce to $\mathrm{m}$ commerce?

\section{Research Model and Hypotheses}

M-commerce is viewed as a subset or an extension to e-commerce, and is closely related to it historically and conceptually [62]. However, while both commerce mediums have the same functionalities in terms of facilitating electronic business transactions over internet, they have fundamental differences. M-commerce and e-commerce can be compared according to four key dimensions: human, product, interface and service related factors [50]. Furthermore, [43] state that both concepts can be distinguished based on several dimensions, namely value, application development, network infrastructure and end-user devices. Similar to [7], e-commerce and m-commerce in this study are distinguished based on aspects related to two main dimensions, namely technology and value. The adopted framework takes into account the technological and value-added characteristics that underline the key differences between e-commerce and m-commerce contexts. Furthermore, it considers the critical role of risk perceptions in switching from e-commerce to $\mathrm{m}$-commerce. The perception of differences in technology between both concepts refers to variances in the perceptions of end-user devices and communication network. In the e-commerce environment, end-user devices, such as personal computers, have sufficient screen size, adequate power supply, rich and effective audio and video, and a standard keyboard. Furthermore, broadband with a high transmission speed is the basic communication network of e-commerce. On the other hand, m-commerce end-user devices, such as smartphones, have small screens, an inadequate power supply and a limited input keyboard. In addition, m-commerce's communication network has a low transmission speed and limited bandwidth. The paper should also include a thorough literature review which places the work in a particular body of academic knowledge. You can use a topical approach to your literature review, or a chronological approach. The former is based on themes, the latter on when the work was written. You should state the previous works relevant to your work, what methods they utilized, how findings are similar or different. You should also indicate where your paper fits and what gap it is actually filling in the literature.

Consumers' perception of value differs when considering the use of $\mathrm{m}$-commerce and e-commerce. [9] emphasise that perceived value is considered as a critical factor in determining users' adoption of emerging internet and mobile internet technologies. [33] p.115 offer a conceptualised definition for the perception of mobile internet value and define it as consumers' overall perception of m-internet based on the consideration of the benefits and sacrifices needed to acquire or use it. Based on [33] definition, differences in perceived value between e-commerce and m-commerce refer to the decision of a trade-off between overall benefits and overall sacrifices. In e-commerce, high speed processing and massive storage is available, whereas $\mathrm{m}$-commerce is characterised by ubiquity, personalisation and locationbased services. Thus, differences in value perception between e-commerce and $\mathrm{m}$-commerce in this study refer to three main aspects: risk, personalisation and convenience. As can be demonstrated in the research model (figure 1), consumers' behavioural intentions to transfer from internet-based e-commerce to $\mathrm{m}$-commerce is influenced by factors related to perceived differences in two key dimensions: technology and value. 




Figure 1: The research model

\subsection{Differences in Perceptions of Channel Risk}

Risk is a deep-rooted concept in the history of information systems and marketing [70]. Perceived risk was first introduced into marketing literature by [5] as a potential measure of consumers' purchase attitude. According to [47], despite the fact that virtual shopping provides consumers with the benefits of convenience, money and time savings, it is subjected to further risks that are not encountered in traditional shopping. [59] point out that examining perceived risk in virtual shopping (i.e. e-commerce, m-commerce) considerably differs from conventional shopping (shopping in store). It takes into account not only the risk that may arise from the product itself, but also considers several risk issues related to online channels and point of purchase. Thus, various dimensions of risk have been identified in the existent literature of e-commerce such as privacy, security, financial, physical, social, performance, and psychological concerns [51], [71]. This study investigates the difference of users' risk perceptions of transactions over both ecommerce and $\mathrm{m}$-commerce channels, particularly focusing on the dimensions of privacy and security.

In an e-commerce environment, privacy and security dimensions are viewed as predominant [39]. Security is an important factor that influences consumers' trust in e-commerce, and security offered by online retailers represents the safety of financial information (i.e. credit cards details). On the other hand, privacy refers to the ability of consumers to control the distribution of their own information when engaging in online transactions, and the capability to control people involved in online transactions.

Perceived risk refers to individuals' perceived uncertainty and adverse repercussion of performing an activity [38]. From the perspective of e-commerce, consumers encounter uncertainty and adverse effects during online shopping [14]. Perceived risk is regarded as the extent to which consumers believe that conducting an online transaction is insecure and may result in negative consequences [39]. The literature of e-commerce highlights perceived risk as a barrier that impacts consumers' use of mobile services and online purchasing behaviour [7]. This is mainly because of the impersonal and distant characteristics of the virtual environment, and is also due to the nature of its open technology infrastructure. Bearing in mind the open nature of the global network environment, transactions in ecommerce are associated with two primary forms of risk: financial and privacy/security risks. According to [11], the privacy/security risk occurs due to the fact that personal/financial information may not be secure when such information is shared over a public network. As a consequence, consumers fear having their personal and financial (i.e. credit card details, bank balance) information collected and used without their consent. Another concern for e-commerce users arises from the fear of hacking, interception or unauthorised use of their personal and financial information [7]. Financial risk is referred to as customers' fear of monetary loss. This may stem from, for example, not receiving products/services after making a payment, or any additional charges that may apply, such as delivery costs, and the possibility that products may require repair [34].

The impact of perceived risk is proven to be influential on consumers' decisions in both e-commerce and m-commerce environments. [68] point out that perceived risk has a negative influence on consumers' desire towards the use of 
mobile payment services. In the context of e-commerce, [42] indicates that financial and security risks have a significant negative influence on consumers' online shopping behaviour. [12] state that risk perception negatively influences consumers' willingness to use both $\mathrm{m}$-commerce and e-commerce.

In respect of wired and wireless communication technologies, mobile and wireless communication networks are technically less secure and less mature than wired ones [7]. The mobility, localisation, personal identity and ubiquitous characteristics of mobile environments allow easier exposure to the data of other users with minimum difficulty. In wired communication networks, it is difficult to penetrate a secured network [18]. Additionally, the capability of hardware devices makes it possible to install security applications into desktop devices. In contrast, in wireless environments, unauthorised access to other devices is slightly easier due to the lack of security provided by specific wireless applications because of hardware limitations. Moreover, there are further obstructions such as limited bandwidth, small screens, low memory and battery power that are directly linked to the usage of $m$-commerce [46]. These gaps lead to consumers' different perceptions of risk between the e-commerce and m-commerce environments. In a secure and mature wired environment, consumers' perceptions of financial and privacy/security risks are expected to be lower than in the wireless environment. Therefore, the increased level of perceived risk will indeed decrease consumers' desire to switch from online channels to mobile channels. Thus, the following hypothesis is formulated:

H1: Consumers who have higher perceptions of risk in undertaking commerce via mobile devices compared to online, are unlikely to shift from e-commerce to $m$-commerce.

\subsection{Differences in Perceptions of Convenience}

As consumers devote less time to shopping and more to other lifestyle activities, their desire for convenience has increased and their attention has turned to adopt virtual shopping mediums such as e-commerce and m-commerce [30]. Webster's Dictionary defines convenience as anything that adds to one's comfort or saves work; useful, handy or helpful device, article, service, etc. The perception of convenience has been viewed as one of the major motivators that drives customers' intentions to use e-commerce [10], and m-commerce [8]. Compared to the offline shopping environment, the use of e-commerce and $\mathrm{m}$-commerce allows consumers to shop conveniently without any restrictions in terms of time and geographical boundaries [41]. Consumers may perceive several benefits of shopping via ecommerce and m-commerce, such as increased convenience due to savings in time and effort, a greater variety of products and brands, and information regarding the availability of products [7]. However, convenience perception is a context-based concept, which means that the perceptions of convenience among consumers can vary among the different settings [31]. Therefore, despite the common similarities between e-commerce and m-commerce, $\mathrm{m}$ commerce amplifies consumers' perceptions of convenience due to its unique characteristics and constraints. These characteristics of m-commerce are inherited from its nature, such as mobility, ubiquity, localisation and personal identity. Ubiquity is viewed as the key advantage of $\mathrm{m}$-commerce. Ubiquity refers to the seamless connectivity regardless of consumers' locations. Through internet-enabled mobile devices, consumers are no longer restricted by time and place, thus they may engage in activities, such as conducting transactions or receiving information, whenever they want. In this sense, m-commerce allows a variety of services and applications to be accessed wherever and whenever the need arises. In contrast, in the context of e-commerce, stationary internet connections are required, and consumers are also constrained by a fixed location to conduct a transaction. Accordingly, the following hypothesis is suggested

H2: Consumers with greater perceptions of convenience in undertaking commerce via mobile devices compared to online, are expected to transfer from e-commerce to $m$-commerce.

\subsection{Differences in Perceptions of Personalisation}

Localisation and personalisation are also important characteristics of $\mathrm{m}$-commerce [44]. Localisation represents the ability of mobile devices to track and recognise the geographical location of users, and thus personalise the available services accordingly. Personalisation emerges from the liaison between the user and the mobile device, such that a mobile device is used by a sole individual. Both features support $\mathrm{m}$-commerce providers to deliver consumers with relevant information, products or services. In addition, such features enable providers to acquire information about consumers' preferences and in turn offer personalised services or products. Identifying a user's location at a particular moment adds a key value to $\mathrm{m}$-commerce over e-commerce. The availability of location information may lead to several location-based services. For instance, utilising the technology of GPS allows m-commerce providers to send and receive information related to a particular location. It also helps users to locate any specific products or services such as the nearest ATM, stores or restaurants. Additionally, based on consumers' purchasing history, demographic information, and information on their current location, m-commerce providers can personalise their advertising, services or products in a targeted way to a specific user. Hence, the following hypothesis is suggested

H3: Consumers with greater perceptions of personalisation in undertaking commerce via mobile devices compared to online, are expected to transfer from e-commerce to $m$-commerce. 


\subsection{Differences in Communication Network Perception}

From a technological perspective, m-commerce has several different characteristics compared to e-commerce. The literature points out such differences originate from two main aspects, namely: end-user device and communication network [7]. M-commerce is based on wireless communication networks that are subject to several limitations compared to the stationary lines used with internet-based e-commerce [67]. For instance, wireless networks have a narrow bandwidth by spectrum. Even though wireless networks (i.e. cellular or satellite networks) may have higher bit rates, they have lower transmission rates than wired networks [43]. Additionally, network connection stability is recognised as one of the major reasons that make wireless networks less reliable [41]. Various factors cause network disconnection, including variations in the mobile signal strength, inadequate network coverage, cell interference and the low battery life of mobile devices [49]. Importantly, m-commerce activities, especially online trading and entertainment, require sustained network connectivity as interrupted network connectivity may lead to negative consequences in the resultant transactions.

H4: Consumers who have higher perceptions in the efficiency of communication networks to undertake commerce via the mobile internet compared to the stationary internet, are expected to transfer from e-commerce to $m$-commerce.

\subsection{Differences in Perceptions of the End-user Device}

In terms of end-user devices, personal computers (PCs) are the main devices used in inter-based e-commerce. PCs possess large screens, have an abundant power supply, appropriate processing and storage capacities, suitable video and audio displays, a standardised keyboard, and broadband communication networks with high transmission speeds [7]. In contrast, mobile devices are subject to several limitations. [57] Summarise these limitations into three main aspects: battery, display, and resources capabilities. In general, mobile devices have a limited lifetime before their energy resources need recharging. Such a drawback prevents mobile devices from executing energy-intensive and complex computations [49]. Furthermore, data transmission via a wireless medium makes battery lifetime shorter as it requires significant energy. Consequently, compared to stationary devices, the availability of mobile devices cannot be assured in a network. Users may be forced to disconnect their wireless connection to save energy consumption, or they may face a situation where the battery of their mobile device becomes unexpectedly flat.

Mobile devices have limited storage, CPU and processing capacities due to the small size of their portability [57]. These issues restrict the amount of processes that can be performed, and the data that can be stored on mobile devices. A small keypad and screen are considered other limitations of mobile devices. Small screens and narrow text input capabilities restrict the volume of information that can be displayed and lead to the increased difficulty of data entry. In view of the limitations of mobile end-user devices and communication networks, consumers are expected to resist $\mathrm{m}$-commerce, consequently traditional e-commerce would be preferred. The following hypothesis is suggested:

H5: Consumers with higher perceptions in the performance of end-user devices to perform commerce via mobile devices compared to online devices, are thought more favourable to transfer from e-commerce to m-commerce.

\section{Methodology}

The research began with a data collection process on 12 November 2016 from undergraduate students at three private universities in Amman, Jordan. The respondents of this study were all university students because they are considered to be the greatest users of mobile devices (m-devices) in Jordan. Also, they are likely to have more experience than other user groups in using m-devices. According to [29], university students' incomes and educational levels make them more likely to be early adopters of new technologies and innovations such as m-commerce. Additionally, students are viewed as 'mobile savvy', which means they can easily use the various applications of mobile devices.

A questionnaire-based survey was used as the main method to gather data. A convenience sampling technique was used to distribute the paper-based, self-administered survey questionnaires to students of different courses within the universities. The process of distributing the questionnaire was supported with the assistance of members of the academic staff. In particular, the lecturers were requested to assist the research by distributing the questionnaire in their classes and collect them after the students had given their responses. The aim and objectives of the study were explained to the students prior to the start of the formal survey. Moreover, further assistance was provided to the students throughout the survey to eliminate invalid response. Overall, a total of 600 questionnaires were distributed. A total of 524 questionnaires were returned, giving a response rate of $87 \%$. Out of 524,12 questionnaires were incomplete, thus they were excluded from further analysis. Additionally, 61 questionnaires represented respondents who had no experience with e-commerce, and in turn these were also excluded. A total of 451 valid questionnaires were obtained. According to [54], the sample size obtained for this study is considered adequate for conducting statistical techniques such as factor analysis and Structural Equation Modelling (SEM).

Table 1 displays the descriptive characteristics of the respondents. Of the respondents, $53 \%$ were male and $47 \%$ were female. Forty-five per cent of the respondents were aged above 20 years old, while $55 \%$ were aged 20 or below. 
Regarding the type of mobile device owned by the respondents, the empirical data shows that all respondents had a $\mathrm{m}$-device. The category of smartphone users was dominant, occupying $68 \%$ of the total sample. Twenty-nine per cent of the respondents had at least two types of m-devices, and $2 \%$ had only mobile phones. In terms of the respondents' courses, these were classified into ten courses. While business administration had the largest number of responders $(n=102)$, pharmacy was the course least represented in the total sample with only 13 responders $(n=13)$. Finally, $77 \%$ of the respondents reported that they did not have $\mathrm{m}$-commerce experience, while $23 \%$ had $\mathrm{m}$-commerce experience in the past.

Table 1: The respondents' profile $(n=451)$

\begin{tabular}{|c|c|c|c|}
\hline Variables & & Frequency & $\%$ \\
\hline \multirow{3}{*}{ Gender $(n=451)$} & Male & 237 & $53 \%$ \\
\hline & Female & 214 & $47 \%$ \\
\hline & Total & 451 & $100 \%$ \\
\hline \multirow{3}{*}{ Age $(n=451)$} & $<=20$ & 247 & $55 \%$ \\
\hline & $>20$ & 204 & $45 \%$ \\
\hline & Total & 451 & $100 \%$ \\
\hline \multirow{4}{*}{ Type of mobile device $(n=451)$} & Mobile phone & 10 & $2 \%$ \\
\hline & Smart phone & 308 & $68 \%$ \\
\hline & $\begin{array}{l}\text { Mobile/ smart phone + Other (i.e. PAD, palmtop, laptop, } \\
\text { etc) }\end{array}$ & 133 & $29 \%$ \\
\hline & Total & 451 & $100 \%$ \\
\hline \multirow{11}{*}{ Course $(n=451)$} & IT related & 73 & $16 \%$ \\
\hline & Business administration & 102 & $23 \%$ \\
\hline & Management information systems & 19 & $4 \%$ \\
\hline & E-business & 38 & $8 \%$ \\
\hline & Engineering related & 24 & $5 \%$ \\
\hline & Nursing & 23 & $5 \%$ \\
\hline & Pharmacy & 13 & $3 \%$ \\
\hline & Law & 36 & $8 \%$ \\
\hline & Architecture and Design & 29 & $6 \%$ \\
\hline & Finance, banking and accounting & 94 & $21 \%$ \\
\hline & Total & 451 & $100 \%$ \\
\hline \multirow{3}{*}{$\begin{array}{l}\text { M-commerce experience } \\
(n=451)\end{array}$} & Yes & 102 & $23 \%$ \\
\hline & No & 349 & $77 \%$ \\
\hline & Total & 451 & $100 \%$ \\
\hline
\end{tabular}

\subsection{Measurements}

Corresponding to [63], in order to attain an adequate degree of content validity, the items employed to measure the constructs of the research model were adapted and modified from related and well-established literature. Table 2 presents the measurement items used in the questionnaire form. These items have been adopted from related research [7], [37], [52]. The questionnaire form consisted of two main parts. The first part aimed at acquiring information about the respondents' demographic data and their usage of mobile devices and e-commerce experience. All measurements adopted in this part were nominal. The followed part aimed at measuring respondents' perception of each construct in the research model; this comprised 18 items. The independent variables were comprised of five constructs with 15 items, whereas the only dependent variable was measured with three items. All items were measured using a four-point Likert scale ranging from 1 strongly agree to strongly disagree. All items were translated into Arabic and slight amendments were made to suit the research's subject. In order to ensure consistency, a translation back was performed. To ensure the questionnaire's content validity and reliability, the first draft of the questionnaire was thoroughly evaluated by a panel of information systems (IS) experts who have a rich knowledge in the field of m-commerce and e-commerce. Based on their recommendations, a few items were reviewed in order to 
make them more precise and accurate. Lastly, a pilot testing (pre-testing) for the final draft of the questionnaire was conducted to modify the ambiguous items. The pilot testing was carried out by presenting the questionnaire to a representative sample of 40 students. All Cronbach's alpha coefficients exceeded the acceptable threshold value of 0.7 recommended by [21], and hence the results indicated the substantial reliability of the questionnaire.

Table 2: Measurement scales

\begin{tabular}{|l|l|}
\hline $\begin{array}{l}\text { Perceived } \\
\text { Convenience (PCO) }\end{array}$ & $\begin{array}{l}\text { PCO1: I can use mobile shopping sites at any time for my transactions. } \\
\text { PCO2: I can use mobile shopping sites from anywhere for my transactions. Wide variety of services is readily accessible via mobile shopping sites. }\end{array}$ \\
\hline $\begin{array}{l}\text { Perceived } \\
\text { Personalisation } \\
\text { (PPE) }\end{array}$ & $\begin{array}{l}\text { PPE1: The advertisements and promotions that this mobile shopping site sends to } \\
\text { me are tailored to my situation. } \\
\text { PPE2: Mobile shopping site make me feel that I am a unique customer. } \\
\text { PPE3: Mobile shopping site enable me to order products or services that are tailor- } \\
\text { made for me. }\end{array}$ \\
\hline $\begin{array}{l}\text { End User Device } \\
\text { (EUD) }\end{array}$ & $\begin{array}{l}\text { EUD1: Mobile shopping with a convenient overall interface. } \\
\text { EUD2: Mobile shopping with a convenient screen. } \\
\text { EUD3: Mobile shopping with a convenient input interface overall. }\end{array}$ \\
\hline $\begin{array}{l}\text { Perceived Risk } \\
\text { (PRI) }\end{array}$ & $\begin{array}{l}\text { PRI1: I would not feel secure sending private personal information on the mobile } \\
\text { internet. } \\
\text { PRI2: If mobile transaction errors were to occur, I worry that I would be unable to get } \\
\text { compensation. } \\
\text { PRI3: I worry about the occurrence of fraud and hacker intrusion while make } \\
\text { transactions on the mobile internet. }\end{array}$ \\
\hline $\begin{array}{l}\text { CNE1: Good initial connection speed of wireless network. } \\
\text { CNE2: Good data transferring speed of wireless network. }\end{array}$ \\
$\begin{array}{l}\text { Consumers' } \\
\text { Intention to Transfer } \\
\text { from e-commerce to } \\
\text { m-commerce (BEI) }\end{array}$
\end{tabular}

\section{Data Analysis and Results}

Following the studies of [35], data analysis of this study consisted of three main steps: exploratory study, confirmatory study and testing the structural model. The exploratory study was performed using SPSS 20 software, whereas the confirmatory study and testing of the structural model were conducted using LISREL 92 statistical software.

\subsection{Exploratory Study}

In this stage, preliminary analyses were performed. These tests included: corrected item-total correlation (CITC), exploratory factor analysis on the whole dataset and reliability evaluation by means of Cronbach alpha $(\alpha)$. The analysis of CITC was performed to purify the constructs' measurement items by detecting insignificant items which may affect the interpretation of the factor analysis [40]. CITC represents a correlation between an item (indicator) and combined score of all the items measuring the same construct. CITC analysis was performed for each construct. As Table 3 demonstrates, all items obtained a CITC coefficient above the recommended edge value of 0.5 [19].

Then, Cronbach's Alpha $(\alpha)$ with a value of 0.7 was employed to assess the reliability of each construct [36]. The coefficients of Cronbach's alpha for all constructs were above 0.7 (see Table 3), and ranged from 0.86 to 0.92 , suggesting that the items measuring each construct (concept) are highly correlated with each other and thus internally consistent. Skewness and Kurtosis statistics were evaluated in order to test the items' Normality. [16] suggest that Skewness and Kurtosis statistics should range between +2 and -2 . As can been seen in Table 3, all items acquired acceptable values of Skewness and Kurtosis statistics, which indicates that all items were normally distributed. 
Table 3: Mean, standard deviation, skew, kurtosis and cronbach alpha

\begin{tabular}{|c|c|c|c|c|c|c|c|}
\hline Construct & Mean & $\begin{array}{l}\text { Standered } \\
\text { Deviation }\end{array}$ & Items & CITC & Skew & Kurtosis & $\alpha$ \\
\hline Perceived Risk (PRI) & 3.5 & 0.89 & $\begin{array}{l}\text { PRI1 } \\
\text { PRI3 } \\
\text { PRI2 }\end{array}$ & $\begin{array}{l}0.86 \\
0.84 \\
0.78\end{array}$ & $\begin{array}{l}-0.53 \\
-0.59 \\
-0.55\end{array}$ & $\begin{array}{l}-0.70 \\
-0.60 \\
-0.61\end{array}$ & 0.91 \\
\hline $\begin{array}{l}\text { Perceived } \\
\text { Convenience (PCO) }\end{array}$ & 1.5 & 0.71 & $\begin{array}{l}\mathrm{PCO} 3 \\
\mathrm{PCO} 2 \\
\mathrm{PCO} 1\end{array}$ & $\begin{array}{l}0.87 \\
0.85 \\
0.78\end{array}$ & $\begin{array}{l}0.96 \\
0.93 \\
0.98\end{array}$ & $\begin{array}{l}-0.68 \\
-0.72 \\
-0.58\end{array}$ & 0.92 \\
\hline $\begin{array}{l}\text { End User Device } \\
\text { (EUD) }\end{array}$ & 1.47 & 0.68 & $\begin{array}{l}\text { EUD3 } \\
\text { EUD1 } \\
\text { EUD2 }\end{array}$ & $\begin{array}{l}0.83 \\
0.76 \\
0.75\end{array}$ & $\begin{array}{l}1.08 \\
1.18 \\
1.43\end{array}$ & $\begin{array}{l}-0.44 \\
-0.2 \\
0.40\end{array}$ & 0.89 \\
\hline $\begin{array}{l}\text { Perceived } \\
\text { Personalisation } \\
\text { (PPE) }\end{array}$ & 1.8 & 0.9 & $\begin{array}{l}\text { PPE1 } \\
\text { PPE2 } \\
\text { PPE3 }\end{array}$ & $\begin{array}{l}0.80 \\
0.79 \\
0.78 \\
\end{array}$ & $\begin{array}{l}0.62 \\
0.85 \\
0.76 \\
\end{array}$ & $\begin{array}{l}-1.13 \\
-0.71 \\
-0.78 \\
\end{array}$ & 0.90 \\
\hline $\begin{array}{l}\text { Communication } \\
\text { Network (CNE) }\end{array}$ & 1.6 & 0.73 & $\begin{array}{l}\text { CNE2 } \\
\text { CNE3 } \\
\text { CNE1 }\end{array}$ & $\begin{array}{l}0.74 \\
0.73 \\
0.72\end{array}$ & $\begin{array}{l}0.86 \\
0.72 \\
1.01\end{array}$ & $\begin{array}{l}-0.96 \\
-1.22 \\
-0.66\end{array}$ & 0.86 \\
\hline $\begin{array}{l}\text { Consumers' } \\
\text { Behavioural } \\
\text { Intention to Transfer } \\
\text { (BEI) }\end{array}$ & 1.41 & 0.62 & $\begin{array}{l}\text { BEI2 } \\
\text { BEI1 } \\
\text { BEI3 }\end{array}$ & $\begin{array}{l}0.87 \\
0.83 \\
0.80\end{array}$ & $\begin{array}{l}1.37 \\
1.23 \\
1.57\end{array}$ & $\begin{array}{l}0.42 \\
0.04 \\
1.19\end{array}$ & 0.92 \\
\hline
\end{tabular}

Then, exploratory factor analysis (EFA) was conducted on the entire dataset. EFA aims at detecting the number of meaningful patterns (factors/constructs) that existwithin the data set by identifying items that do not belong to their theoretical constructs, or items that do not have a common core [35]. Before conducting an EFA, it was important to decide whether factor analysis was suitable for the current dataset. Therefore, the Kaiser-Meyer-Oklin (KOM) test of sampling adequacy and Bartlett's test of Sphericity were performed. According to [32], the minimum acceptable KOM value is 0.6 , and Bartlett's test of Sphericity should have a p-value of $<0.05$. The KOM value for the current dataset was 0.827 . The Bartlett's test of Sphericity was inspected using the Chi-Square statistic which was 6883.067 and was significant at the $0 \%$ level $(X 2=6883.067, p<0.001)$. Such results indicate that the dataset is eligible to conduct an EFA.

For the EFA, a principal axis factoring with Promax oblique solution and eigenvalue greater than 1 and factor loadings greater than 0.5 was performed [20]. As can be seen in Table 4, the results of the EFA suggest that 6 factors (constructs) were extracted with eigenvalues greater than 1 . The results also show that the loadings of the entire measurement items on their associated factors were above 0.5 . Overall, the 6 factors underlying the whole dataset accounted for $83.76 \%$ of the explained variance.

\subsection{Confirmatory Study (Measurement Model)}

Despite the usefulness of the techniques used in exploratory factor analysis (EFA) in the early stages of analysing the empirical data, these techniques do not examine uni-dimensionality [40]. The main goal of EFA was exploration, where theoretical models do not exist. Therefore, confirmatory factor analysis (CFA) was performed on the complete set of items simultaneously to assess the measurement model of this study.

The overall model fit was examined through seven goodness-of-fit indices. Table 5 represents all these indices along with their recommended coefficients. As suggested by [19], the results indicate that all coefficients of the goodnessof-fit indices met the recommended values, demonstrating a good fit between that the measurement model with the dataset collected. 
Table 4: Exploratory factor analysis

\begin{tabular}{|c|c|c|c|c|c|c|c|}
\hline \multirow{2}{*}{ Construct } & \multirow{2}{*}{ Items } & \multicolumn{6}{|c|}{ Factor } \\
\hline & & 1 & 2 & 3 & 4 & 5 & 6 \\
\hline \multirow{3}{*}{ Perceived Risk (PRI) } & PRI1 & 0.92 & & & & & \\
\hline & PRI3 & 0.91 & & & & & \\
\hline & PRI2 & 0.88 & & & & & \\
\hline \multirow{3}{*}{ Perceived Convenience (PCO) } & PCO3 & & 0.91 & & & & \\
\hline & $\mathrm{PCO} 2$ & & 0.90 & & & & \\
\hline & PCO1 & & 0.88 & & & & \\
\hline \multirow{3}{*}{ End User Device (EUD) } & EUD3 & & & 0.92 & & & \\
\hline & EUD1 & & & 0.85 & & & \\
\hline & EUD2 & & & 0.84 & & & \\
\hline \multirow{3}{*}{ Perceived Personalisation (PPE) } & PPE1 & & & & 0.89 & & \\
\hline & PPE2 & & & & 0.88 & & \\
\hline & PPE3 & & & & 0.86 & & \\
\hline \multirow{3}{*}{ Communication Network (CNE) } & CNE2 & & & & & 0.87 & \\
\hline & CNE3 & & & & & 0.86 & \\
\hline & CNE1 & & & & & 0.82 & \\
\hline \multirow{6}{*}{$\begin{array}{l}\text { Consumers' Behavioural Intention to } \\
\text { Transfer (BEI) }\end{array}$} & BEI2 & & & & & & 0.84 \\
\hline & BEl1 & & & & & & 0.83 \\
\hline & BEI3 & & & & & & 0.79 \\
\hline & Eigenvalue & 6 & 2.57 & 2.13 & 1.96 & 1.42 & 1 \\
\hline & $\begin{array}{l}\% \text { of Variance } \\
\text { Explained }\end{array}$ & 33.35 & 14.27 & 11.81 & 10.91 & 7.86 & 5.56 \\
\hline & Cumulative\% & 30.71 & 47.62 & 59.43 & 70.34 & 78.2 & 83.76 \\
\hline
\end{tabular}

Table 5: Fit indices

\begin{tabular}{|l|l|l|l|}
\hline Fit indices & $\begin{array}{l}\text { Recommended } \\
\text { value }\end{array}$ & $\begin{array}{l}\text { Measurement } \\
\text { model }\end{array}$ & $\begin{array}{l}\text { Structural } \\
\text { Model }\end{array}$ \\
\hline$X^{2} /$ df (Chi square/degree of freedom) & $\leq 3$ & 2.05 & 1.93 \\
\hline GFI (comparative fit index) & $\geq 0.90$ & 0.95 & 0.96 \\
\hline GFI (goodness of fit index) & $\geq 0.90$ & 0.88 & 0.91 \\
\hline RMSEA (root mean square error of approximation) & $\leq 0.08$ & 0.07 & 0.05 \\
\hline RMR (root mean square residual) & $\leq 0.1$ & 0.06 & 0.07 \\
\hline NFI (normed fit index) & $\geq 0.90$ & 0.96 & 0.97 \\
\hline NNFI (non-normed fit index) & $\geq 0.90$ & 0.95 & 0.96 \\
\hline
\end{tabular}

CFA can also be utilised to evaluate the reliability, discriminant validity and convergent validity. Convergent validity assesses whether the measurement items of theoretically similar constructs are highly inter-correlated [65]. On the other hand, discriminant analysis aims to ensure that measurement items of theoretically distinct constructs are not strongly interrelated [23]. Corresponding to [6], convergent validity was examined by assessing the items' loadings and their t-values. A t-value $>1.96$ or $<-1.96$ designates significance. The items' reliability was evaluated by assessing each item's squared multiple correlation (SMC). [64] point out that SMC values $\geq 0.5$ indicate evidence of adequate

Ahmad Samed Al-Adwan Mohammad Alrousan Anas Al-Soud Hussein Al-Yaseen 
reliability. Table 6 demonstrates that all items exhibited SMC higher than 0.5 and thus all items acquired individual reliability.

Convergent validity was also evaluated by calculating the average variance explained (AVE). According to [17], the AVE values signify the average extent of variance in a latent construct that is explained by the observed variables to which it is theoretically related. [20] suggest that AVE values that are $\geq 0.5$ is used as a rule of thumb to indicate considerable convergence. Composite reliability is used to interpret true estimations of reliability for all constructs and should be $\geq 0.7$ [22]. Additionally, the readings of cross-loadings were observed in order to determine whether they are remarkably high to be alarming. The results indicate that items loaded significantly on their associated constructs (factors) as the least loading value was 0.87. The results in Table 6 also show that the AVE values of all constructs exceeded the cut-off value of 0.5 . Such results provide evidence of convergent validity as all items were considerably associated with their theoretical constructs. Furthermore, the results indicate that all constructs acquired adequate composite reliability of 0.7 [22].

Table 6: Confirmatory factor analysis

\begin{tabular}{|c|c|c|c|c|c|c|}
\hline Construct & Items & $\begin{array}{l}\text { Factor } \\
\text { loading }\end{array}$ & t-value & SMCa $^{a}$ & $\mathbf{C R}^{\mathrm{b}}$ & AVEc $^{c}$ \\
\hline \multirow{3}{*}{ Perceived Risk (PRI) } & PRI1 & 0.94 & 126.58 & 0.88 & \multirow{3}{*}{0.94} & \multirow{3}{*}{0.85} \\
\hline & PRI3 & 0.93 & 92.39 & 0.86 & & \\
\hline & PRI2 & 0.89 & 54.12 & 0.79 & & \\
\hline \multirow{3}{*}{ Perceived Convenience (PCO) } & PCO3 & 0.94 & 113.85 & 0.88 & \multirow{3}{*}{0.95} & \multirow{3}{*}{0.86} \\
\hline & PCO2 & 0.93 & 110.49 & 0.86 & & \\
\hline & PCO1 & 0.9 & 59.32 & 0.81 & & \\
\hline \multirow{3}{*}{ End User Device (EUD) } & EUD3 & 0.92 & 83.1 & 0.85 & \multirow{3}{*}{0.92} & \multirow{3}{*}{0.81} \\
\hline & EUD1 & 0.9 & 63.56 & 0.81 & & \\
\hline & EUD2 & 0.89 & 60.01 & 0.79 & & \\
\hline \multirow{3}{*}{ Perceived Personalisation (PPE) } & PPE1 & 0.93 & 140.41 & 0.86 & \multirow{3}{*}{0.93} & \multirow{3}{*}{0.82} \\
\hline & PPE2 & 0.9 & 68.44 & 0.81 & & \\
\hline & PPE3 & 0.89 & 61.4 & 0.79 & & \\
\hline \multirow{3}{*}{ Communication Network (CNE) } & CNE2 & 0.89 & 62.48 & 0.79 & \multirow{3}{*}{0.91} & \multirow{3}{*}{0.78} \\
\hline & CNE3 & 0.88 & 50.81 & 0.77 & & \\
\hline & CNE1 & 0.87 & 49.45 & 0.76 & & \\
\hline \multirow{3}{*}{$\begin{array}{l}\text { Consumers' Behavioural Intention to } \\
\text { Transfer (ITB) }\end{array}$} & ITB2 & 0.95 & 109.9 & 0.9 & \multirow{3}{*}{0.95} & \multirow{3}{*}{0.86} \\
\hline & ITB1 & 0.94 & 77.48 & 0.88 & & \\
\hline & ITB3 & 0.91 & 50.19 & 0.83 & & \\
\hline
\end{tabular}

${ }^{*} \mathrm{CR}=\left(\sum \lambda\right) 2 /\left(\sum \lambda\right) 2+\left(\sum \Theta \mathrm{i}\right), \lambda=$ factor loading, $\theta=$ measurement error of each measured variable

${ }^{*} \mathrm{AVE}=\left(\sum \lambda 2\right) /\left[\left(\sum \lambda 2\right)+\sum \Theta\right], \lambda=$ factor loading, $\Theta=$ measurement error of each measured variable

aSMC: squried multiple correlation, bCR: composite reliability, c AVE:avrage variance extracted

Discriminant analysis was examined by comparing AVE values of each construct with the squared correlations between constructs. [55] point out that discriminant validity evidently exists when the shared variance between each construct and its items must be higher than the shared variance between the construct and any other constructs. [20] p.778 suggest to prove that discriminant validity is existent the variance extracted estimates should be greater than the squared correlation estimate. As can be shown in Table 7, the squared correlations of each construct with all other constructs is substantially lower than the value of AVE for each construct (in bold). Hence, adequate discriminant validity is demonstrated for the research model. 
Table 7: Discriminant analysis

\begin{tabular}{|c|c|c|c|c|c|c|}
\hline Construct & $\mathrm{BEI}$ & $\mathrm{PCO}$ & PRI & EUD & CNE & PPE \\
\hline $\mathrm{BEI}$ & $0.86^{\mathrm{a}}$ & & & & & \\
\hline \multirow[t]{2}{*}{$\overline{P C O}$} & $0.284^{b}$ & \multirow[t]{2}{*}{0.86} & & & & \\
\hline & $(0.081)^{C}$ & & & & & \\
\hline \multirow[t]{2}{*}{ PRI } & -0.372 & -0.115 & \multirow[t]{2}{*}{0.85} & & & \\
\hline & $(0.138)$ & $(0.013)$ & & & & \\
\hline \multirow[t]{2}{*}{ EUD } & 0.473 & 0.194 & -0.185 & \multirow[t]{2}{*}{0.81} & & \\
\hline & $(0.224)$ & $(0.038)$ & $(0.034)$ & & & \\
\hline \multirow[t]{2}{*}{ CNE } & 0.466 & -0.018 & -0.143 & 0.311 & \multirow[t]{2}{*}{0.78} & \\
\hline & $(0.217)$ & $(0.0003)$ & $(0.021)$ & $(0.097)$ & & \\
\hline \multirow[t]{2}{*}{ PPE } & 0.335 & 0.183 & -0.125 & 0.107 & 0.242 & \multirow[t]{2}{*}{0.82} \\
\hline & $(0.112)$ & $(0.033)$ & $(0.016)$ & $(0.011)$ & $\begin{array}{l}(0.059) \\
\end{array}$ & \\
\hline
\end{tabular}

${ }^{a}$ AVE: average variance extracted, ${ }^{b}$ correlations between constucts, ${ }^{c}$ Squared correlation

\subsection{Structural Model}

The model's overall fitness with the data was evaluated. As Table 5 above shows, the estimated fit indices were all within their corresponding recommended values, suggesting that the research model evidently obtained a reasonable fit with the data. With the fit indices of the structural model revealed and accepted, path coefficients of the structural model were then assessed to examine the hypotheses. In Figure 2, the coefficient of determination (R2), standardised paths coefficient and their t-values are displayed. The results reveal that the coefficient of determination is 0.68 for the construct of consumers' behavioural intention to transfer (BEI). This means that the 5 latent variables of the research model explain $68 \%$ of the variance in BEl. Figure 2 also shows that all of the proposed hypotheses were significantly supported. Perceived differences in communication network (CNE) $(\beta=0.395, t=7.68)$ was identified as strongest positive determinant to consumers' behavioural intention to transfer (ITB), whereas perceived differences in risk (PRI) $(\beta=-0.332, t=6.48)$ had the strongest negative effect on $B E I$. The results are further discussed in the following section, as well as the implications of the study.



Figure 2: Hypotheses testing

Ahmad Samed Al-Adwan Mohammad Alrousan Anas Al-Soud Hussein Al-Yaseen 


\section{Discussion and Implications}

With regard to perceived differences in technology, both m-commerce and traditional (internet-based) e-commerce were distinguishable based on several aspects, including perceived differences in communication network and enduser device. Consistent with [7], the results showed that both differences in the perception of end-user devices $(\beta=0.261, t=4.86)$ and differences in communication network perception $(\beta=0.395, t=7.68)$ positively influenced consumers' intention to switch from traditional e-commerce to m-commerce. Such findings indicate that compared to end-user devices and communication networks in traditional e-commerce, if consumers perceive mobile end-user devices are easier to use, and mobile communication networks are steadier with adequate speed, then the shift from online to mobile channels would be favourable.

In fact, consumers can conduct m-commerce transactions through two main modes: using a mobile friendly version of a site and a standard mobile web browser, or by using a particular mobile application. Mobile devices are heterogeneous in terms of capabilities such as computation process, screen size, content access and storage capacity [26]. In addition to the capabilities of mobile devices, the heterogeneity of mobile devices includes aspects such as operating systems and network technologies [56]. For instance, the operating systems of some devices do not meet some of the current needs of $\mathrm{m}$-commerce because they have limited functionalities. Therefore, such notions suggest that developers should re-visit both software applications and operating systems on different platforms to create system software that operates effectively, especially in light of the limited capabilities of mobile devices. Furthermore, the content of $\mathrm{m}$-commerce applications and websites should be transcoded in order to be effectively viewed and accessed by consumers from any device from anywhere, at any time [25]. Another aspect that should be considered by developers is the usability of mobile devices, especially in light of the limited capabilities of such devices. To develop usable m-commerce websites and applications, organisations need to identify how consumers can smoothly access information and use applications through different devices. Manufacturers of mobile devices can produce devices with larger screen sizes and soft keyboards that pop-up on screen. Furthermore, to overcome batteries suddenly running out, the availability of cell phone charging stations should be considered.

Although the results showed that the connectivity of mobile networks is in a satisfactory condition, telecommunication companies should ensure that they have a suitable infrastructure that offers instant connection with adequate security, speed and bandwidth. They also need to strengthen wireless connections and avoid signal dead spots. As suggested by [53], all of the above-mentioned strategies can be addressed by effective cooperation between standardisation parties including telecommunication companies, device manufacturers and $\mathrm{m}$-commerce service developers.

In terms of perceived differences in value, the results indicated that convenience perception $(\beta=0.268, t=4.95)$, and perceived personalisation $(\beta=0.29, t=5.93)$ had positive influences on consumers' intention to switch from traditional e-commerce to m-commerce. Thus, convenience and personalisation, as special features of $\mathrm{m}$-commerce, can be significant boosters of $\mathrm{m}$-commerce growth and development, which agrees with prior research [7], [15]. Convenience has a key role in consumers' choices. M-commerce targets the utilisation of mobile devices and wireless networks with e-commerce systems which allow consumers to experience convenient, instant and appropriate shopping at an unstructured time and place. These results magnify the importance of the ubiquitous wireless environment of $m$ commerce in accomplishing consumers' desires and transactions more conveniently than internet-based e-commerce. This can be justified by the fact that the capabilities of internet-based e-commerce, which used to be accessible solely through personal computers, are now conveniently available on mobile devices. Additionally, it has been found that convenience has a positive impact on the frequency of use of mobile devices [52], which can be among the facilitating factors in shifting from traditional e-commerce to m-commerce. Thus, to increase consumers' convenience of accessing all types of mobile services anywhere at any time, it is important that mobile service providers offer a wide range of mobile services that address the various needs of consumers, while ensuring the stability of connections.

The results prove that perceived personalisation is one of crucial strengths of $\mathrm{m}$-commerce. M-commerce offers services that are personalised to each individual, ranging from tailor-made products to location-based services. Mobile service providers should bear in mind the importance of offering personalised services to address consumers' needs and preferences. To do so, it is critical for mobile service providers and developers to understand the relationship between consumers' demographic profiles and m-commerce in order to personalise services and products, and thus increase m-commerce adoption.

As stated previously, one of the main challenges is that the screens of mobile devices are small, thus they can only display a very limited number of lines of characters. If consumers receive several messages, they are forced to use limiting keypads with small buttons to scroll up and down to read such messages. Furthermore, mobile device users are commonly reluctant to enter a large amount of data due to difficulties in keypad usage. Subsequently, consumers are more likely to become frustrated and impatient when they read many useless and general advertising messages on limited screens. Personalisation seems to be the solution to control the phenomenon of information-flooding [24]. The objective of personalisation is to provide a one-to-one relationship with each consumer by offering them relevant content. With personalisation, the number of messages and irrelevant services sent to consumers will diminish. With smaller and relevant messages, consumers can view messages more conveniently. Consequently, it seems that personalisation can solve the problem of data entry via limited screen sizes on mobile devices. As a result, developers 
of $\mathrm{m}$-commerce applications should understand the relationship between $\mathrm{m}$-commerce and the characteristics and preferences of consumers to personalise services and messages, thus increasing the adoption of $m$-commerce.

Supported by [4], [7], the findings suggested that risk perception is considered as a major barrier to m-commerce adoption. This result contradicts with [1] who found perceived risk (privacy and security concerns) was not significant. The findings reveal that perceived differences in risk perceptions $(\beta=-0.332, t=6.48)$ between traditional e-commerce and $\mathrm{m}$-commerce were found to have a negative impact on consumers' behavioural intention to shift from online to mobile channels. Such a result indicates that consumers' intention to transfer from traditional e-commerce to $\mathrm{m}$ commerce is significantly impacted by the degree of risk they perceive when using $\mathrm{m}$-commerce. The literature has identified several factors that trigger risk perceptions when it comes to $\mathrm{m}$-commerce adoption.

According to [49] [61], several risk-related factors discourage consumers from adopting and using m-commerce, such as concerns related to legislation, privacy, product quality and m-payments. In terms of privacy, taking into account that mobile devices are more susceptible to destruction, loss and theft, protecting confidential data (i.e. credit card details) on mobile devices as well as the devices themselves from unauthorised access and use, is viewed as one of the main concerns of consumers. Performing m-commerce transactions and $\mathrm{m}$-payments through wireless networks (radio interface) is inherently insecure compared to wired networks. Such a weakness represents another security threat (i.e. eavesdropping) in terms of protecting the transmitted data's authenticity, integrity and confidentiality [53]. The payment system is another issue, especially for $\mathrm{m}$-commerce applications that involve mobile payments. Both consumer and merchants need secure payment systems that ensure secure information and financial transactions. Additionally, consumers may have negative intentions to adopt $\mathrm{m}$-commerce because of the mismatch between the quality of the delivered products and what was anticipated [61]. Furthermore, another risk perception is that consumers may fear that they are not protected by clear m-commerce legislation.

Therefore, in order to reduce consumers' risk perception several actions can be taken by online vendors and developers of m-commerce applications. Online vendors should gain consumers' trust by building a considerable reputation, avoid misleading information, and develop comprehensive policies in terms of privacy, the return of goods and fraud protection. Governments should also be directly involved in forming a regulatory framework to suit the $\mathrm{m}$ commerce environment. Developers of $\mathrm{m}$-commerce applications should bear in mind that there is no $\mathrm{m}$-commerce without the security of the underlying technologies. Thus, providing quality information to reduce anxiety, and building effective security systems of m-commerce websites and applications should be their main priority. Accordingly, potential financial losses and the exposure of consumers' privacy in the m-commerce environment requires practitioners and online vendors to clearly declare how consumers' data will be used and handled. Online vendors engaged in financial transactions should offer advanced security encryption, or they may assign the task of securing such transactions to a third party which has experience in safeguarding the security of monetary transactions.

Although this study offers various academic contributions and practical implications, it is subject to a few limitations that can be addressed by further studies in the future. Firstly, the sample of this study was from Jordan, which consequently questions the generalizability of the findings into other cultures. National culture is recognised as a significant factor that influences the development, use and adoption of information technology. Therefore, subsequent studies are needed to investigate the findings of this study in different cultures. Secondly, this study was cross-sectional and quantitative in nature, which means that the research model has been tested and validated based on data captured at a particular period of time. Indeed, beliefs and perceptions can quickly change, accompanied by consumers gaining more experience and rapid technical updates. Thus, mix method longitudinal studies can be conducted to apply the study model in various points of time and consequently generate a more holistic understanding of the factors that drive the behaviour of consumers' intention to transfer [2]. Lastly, future research may examine the moderating effects of consumers' demographics on behavioural intentions to transfer from traditional e-commerce to m-commerce, and thus yield useful and rich insights. Equally, it would be useful to study other aspects such as subjective norms and seller reputation on consumers' intentions to switch from traditional e-commerce to m-commerce.

\section{Conclusion}

This research aimed to investigate the factors that influence consumers' intention to shift from traditional (internetbased) e-commerce to m-commerce. This study focused on key features that distinguish traditional e-commerce from $\mathrm{m}$-commerce. The study was precisely designed to explore the influence of a set of factors related to different traits of $\mathrm{m}$-commerce and traditional e-commerce on consumers' intention to switch from online to mobile channels. The results demonstrate that consumers' intention to shift from e-commerce to m-commerce is influenced by: perceived differences in communication networks, perceived differences in end-user devices, perceived differences in convenience, perceived personalisation and perceived differences in risk. These factors were grouped into two main categories: perceived differences in technology and perceived differences in value. With regard to perceived differences in technology, differences in perceiving communication networks and end-user devices were found to have a significant positive influence on consumers' intention to shift from traditional e-commerce to m-commerce. In terms of perceived differences in value, the findings indicated consumers' intention to switch from traditional e-commerce to $\mathrm{m}$-commerce can be determined by perceived differences in convenience, personalisation and risk perceptions. While perceived differences in convenience and personalisation had significant and positive influences on consumers' intentions towards the use of $\mathrm{m}$-commerce over traditional e-commerce, perceived risk perceptions had a negative 
impact on consumers' intention to transfer behaviours. Indeed, the findings of this study can help practitioners to understand consumers' intention to transfer from traditional e-commerce to m-commerce. Furthermore, the findings can be used to guide online vendors and developers of mobile applications in their efforts to develop an effective and adoptable m-commerce environment.

\section{Acknowledgments}

We would like to thank the faculty of Information Systems and Electronic Commerce Departments at Al Ahliyya Amman University, Jordan. Many thanks go to Professor Asim El Sheikh for his valuable academic guidance and constructive recommendations throughout the different stages of writing this paper. We would also like to thank Dr. Amer Al-Adwan from Hamad Bin Khalifa University, Qatar for his useful comments and guidance during the writing-up of this paper.

\section{Reference}

[1] E. Abu-Shanab and O. Ghaleb, Adoption of mobile commerce technology: An involvement of trust and risk concerns, International Journal of Technology Diffusion, vol. 3, no. 2, pp. 36-49, 2012.

[2] A. Al-Adwan, Case study and grounded theory: A happy marriage? An exemplary application from healthcare informatics adoption research, International Journal of Electronic Healthcare, vol. 9, no. 4, pp. 294-318, 2017.

[3] F. Al Mashagba, E. Al Mashagba and M. Nassar, Exploring technological factors affecting the adoption of Mcommerce in Jordan, Australian Journal of Basic and Applied Sciences, vol. 7, no. 6, pp. 395-400, 2013.

[4] M. Anjali, R. Kumra and V. Srivastava, Determinants of consumer acceptance of $\mathrm{m}$-commerce, South Asian Journal of Management, vol. 20, no. 2, pp. 102-126, 2013.

[5] R. Bauer, Consumer behaviour as risk-taking in Dynamic Marketing for a Changing World, (R.S. Hancock, Ed.). Chicago, IL: American Marketing Association, 1960, pp. 389-398.

[6] B. Byrne, Structural Equation Modeling with AMOS: Basic Concepts, Applications, and Programming. London: Routledge, 2001.

[7] Y. Cao, Y. Lu, S. Gupta and S. Yang, The effects of differences between e-commerce and m-commerce on the consumers' usage transfer from online to mobile channel, International Journal of Mobile Communications, vol. 13, no. 1, pp. 51-70, 2015.

[8] Z. Chen, R. Li., X. Chen, and H. Xu, A survey study on consumer perception of mobile commerce applications, Procedia Environmental Sciences, vol. 11, no. 1, pp. 118-124, 2011.

[9] J. Cheng, E. Wang, J. Lin, and S. Vivek, Why do customers utilize the internet as a retailing platform? A view from consumer perceived value, Asia Pacific Journal of Marketing and Logistic, vol. 21, no. 1, pp. 144-160, 2009.

[10] Y. Cho, Exploring factors that affect usefulness, ease of use, trust, and purchase intention in the online environment', International Journal of Management and Information Systems, vol. 19, no. 1, pp. 21-36, 2015.

[11] C. Comegys, M. Hannula and J. Väisänen, Effects of consumer trust and risk on online purchase decisionmaking: A comparison of finnish and United States students, International Journal of Management, vol. 26, no. 2, pp. 295-308, 2009.

[12] B. Cozzarin and S. Dimitrov, Mobile commerce and device specific perceived risk, Electronic Commerce Research, vol. 16, no.3, pp. 335-354, 2015.

[13] C. Dan, Electronic commerce: state-of-the-art, American Journal of Intelligent Systems, vol. 4, no. 4, pp. 135$141,2014$.

[14] S. Dillon, J. Buchanan and K. Al- Otaibi, Impact of gender and product type on percived risk and online shopping intentions in Encyclopaedia of E-commerce Development, Implementation, and Management (I. Lee Ed.). Hersbey: IGI Global, 2016, pp. 1643-1662.

[15] K. Fong and S. Wong, Factors influencing the behaviour intention of mobile commerce service users: an exploratory study in Hong Kong, International Journal of Business and Management, vol. 10, no. 7, pp. 39-47, 2015.

[16] F. Gravetter and L. Wallnau, Essentials of Statistics for the Behavioural Sciences. Belmont: Wadsworth, 2014.

[17] D. Gefen, D. Straub and M. Boudreau, Structural equation modelling and regression: Guidelines for research practice, Communications of AIS, vol. 4, no. 7, pp. 1-80, 2000.

[18] R. Gururajan, A discussion on security risks in mobile commerce, E-Business Review, vol. 7 no. 2, pp. 9-39, 2006.

[19] J. Hair, Multivariate Data Analysis. New Jersey: Prentice Hall, 1998

[20] S. Hair, C. Black, E. Anderson, and L. Tatham, Multivariate Data Analysis. New York: Prentice-Hall, 2006.

[21] J. Hair, W. Black, B. Babin and A. Anderson, Multivariate Data Analysis. New Jersey: Prentice Hall, 2010.

[22] F. Hair, G. Hult and M. Ringle, A Primer on Partial Least Squares Structural Equation Modeling (PLS-SEM). Thousand Oaks: Sage publications, 2013.

[23] J. Henseler, C. Ringle and M. Sarstedt, A new criterion for assessing discriminant validity in variance-based structural equation modeling, Journal of the Academy of Marketing Science, vol. 43, no. 1, pp. 115-135, 2015.

[24] S. Ho and S. Kwok, The attraction of personalised service for users in mobile commerce: an empirical study, ACM SIGecom Exchanges, vol. 3, no. 4, pp. 10-18, 2003.

[25] M. Hossain, QoS-based service composition for distributed video surveillance, Multimedia Tools and Applications, vol. 73, no. 1, pp. 169-188, 2014. 
[26] M. Hossain, A. Alamri and A. Saddik, A biologically inspired framework for multimedia service management in a ubiquitous environment, Concurrency Computation: Practice and Experience, vol. 21, no. 11, pp. 1450-1466, 2009.

[27] C. Hsieh, Mobile commerce: Assessing new business opportunities, Communications of the IIMA, vol. 7, no. 1, pp. 87-100, 2007.

[28] A. Jahanshahi, A. Mirzaie and A. Asadollahi, Mobile commerce beyond electronic commerce: Issue and challenges, Asian Journal of Business Management Sciences, vol. 1, no. 2, pp.119-129, 2012.

[29] M. Jaradat and K. Faqih, Investigating the moderating effects of gender and self-efficacy in the context of mobile payment adoption: A developing country perspective, International Journal of Business Management, vol. 9, no. 11, pp. 147-169, 2014

[30] L. Jiang, Z. Yang and M. Jun, Consumer perceptions of e-service convenience: An exploratory study, Procedia Environmental Sciences, vol. 11, no. 1, pp. 406-410, 2011.

[31] L. Jiang, Z. Yang and M. Jun, Measuring consumer perceptions of online shopping convenience, Journal of Service Management, vol. 24, no. 2, pp. 191-214, 2013.

[32] F. Kaiser, An index of factorial simplicity, Psyhometrika, vol. 39, no. 1, pp. 31-36, 1974.

[33] H. Kim, H. Chan and S. Gupta, Value-based adoption of mobile internet: an empirical investigation, Decision Support Systems, vol. 43, no. 1, pp.111-126, 2007.

[34] H. Ko, J. Jung, J. Kim, and S. Shim, Cross-cultural differences in perceived risk of online shopping, Journal of Interactive Advertising, vol. 4, no. 2, pp. 20-29, 2004.

[35] Y. Kuo, C. Wu and W. Deng, The relationships among service quality, perceived value, customer satisfaction, and post-purchase intention in mobile value-added services, Computers in Human Behaviour, vol. 25, no. 4, pp. 887-896, 2009

[36] K. Kwong and K. Wong, Partial least squares structural equation modeling (PLS-SEM) techniques using SmartPLS, Marketing Bulletin, vol. 24, no. 1, pp. 1-32, 2013

[37] T. Lee, The impact of perceptions of interactivity on customer trust and transaction intentions in mobile commerce, Journal of Electronic Commerce Research, vol. 6, no. 3, pp. 165-180, 2005.

[38] R. Li, J. Kim and J. Park, The effects of internet shoppers' trust on their purchasing intention in China, Journal of Information Systems and Technology Management, vol. 4, no. 3, pp. 269-286, 2007.

[39] K. Ling, Perceived risk, perceived technology, online trust for the online purchase intention in Malaysia', International Journal of Business and Management, vol. 6, no. 6, pp. 167-182, 2011

[40] C. Lu, K. Lai and T. Cheng, Application of structural equation modelling to evaluate the intention of shippers to use internet services liner shipping, European Journal of Operational Research. vol. 180, no. 2, pp. 845-867, 2007.

[41] H. Lu and P. Su, Factors affecting purchase intention on mobile shopping web sites, Internet Research, vol. 19, no. 4 , pp. $442-458,2009$

[42] E. Masoud, The effect of perceived risk on online shopping in Jordan, European Journal of Business and Management, vol. 5, no. 6, pp. 76-87, 2013.

[43] Q. Min, S. Ji and G. Qu, Mobile commerce user acceptance study in China: A revised UTAUT model, Tsinghua Science and Technology, vol. 13, no. 3, pp. 257-264, 2008.

[44] S. Nandan, Mobile commerce applications and services, International Journal of Engineering and Computer Science, vol. 2, no. 10, pp. 3061-3065, 2013

[45] M. Nassar, Mobile devices usage in Jordanian Banking sector: Critical success factors based on an improved technology acceptance model (TAM), International Journal of Sciences: Basic and Applied Research, vol. 7, no. 1, pp. 93-103, 2013.

[46] M. Niranjanamurth, N. Kavyashree and C. Dharmendra, Analysis of e-commerce and m-commerce: Advantages, limitations and security issues, International Journal of Advanced Research in Computer and communication Engineering, vol. 2, no. 6, pp. 2360-2370, 2013.

[47] G. Noort, P. Kerkhof and B. Fennis, Online versus conventional shopping: Consumers' risk perception and regulatory focus, CyberPsychology \& Behavior, vol. 10, no. 5, pp. 731-733, 2007.

[48] P. Omonedo and P. Bocij, E-commerce versus m-commerce: Where is the dividing line?, International Journal of Social, Behavioural, Educational, Business and Industrial Engineering, vol. 8, no. 11, pp. 3610-3615, 2014.

[49] H. Osman and H. Taylor, Towards a reference model for m-commerce over ad hoc wireless networks, presented at E-Activity and Leading Technologies Conference, Madrid, December 3-5, 2008, pp. 223-232.

[50] A. Ozok and J. Wei, An empirical comparison of consumer usability preferences in online shopping using stationary and mobile devices: results from a college student population, Electronic Commerce Research, vol. 10, no. 2, pp. 111-137, 2010.

[51] G. Rajini G and M. Krithika, Online purchase: Risk cognizance influencing intention, Indian Journal of Science and Technology, vol. 9, no. 32, pp. 1-4, 2016.

[52] Z. Saleh and A. Mashhour, Consumer attitude towards M-commerce: The perceived level of security and the rule of trust, Journal of Emerging Trends in Computing and Information Sciences, vol. 5, no. 2, pp. 111-117, 2014.

[53] S. Schwiderski-Grosche and H. Knospe, Secure mobile commerce, Electronic \& Communication Engineering Journal, vol. 14, no. 5, pp. 228-238 2002.

[54] K. Siddiqui, Heuristics for sample size determination in multivariate statistical techniques, World Applied Sciences Journal, vol. 27, no. 2, pp. 285-287, 2013.

[55] Smith, P. Duchessi and J. Garcia, Information sharing and business systems leveraging in supply chains: An empirical investigation of one web-based application, Information \& and management, vol. 49, no. 1, pp. 58-67, 2012. 
[56] P. Tarasewich, R. Nickerson and W. Merrill, Wireless/Mobile E-Commerce: Technologies, Applications, and Issues, in Proceedings 7th Annual AMCIS Conference on Information Systems and Information Technology, Boston, 2001, pp. 435-438.

[57] P. Tarasewich, C. Nickerson and M. Warkentin, Issues in mobile e-commerce, Communications of the Association for Information Systems, vol. 8, no.1, pp. 41-64, 2002.

[58] R. Tiwari, S. Buse and C. Herstatt, From electronic to mobile commerce: Opportunities through technology convergence for business services, CACCI Journal, vol. 1, no. 1, pp. 1-12, 2008.

[59] G. Torkzadeh and G. Dhillon, Measuring factors that influence the success of Internet commerce, Information Systems Research, vol. 13 no. 2 pp. 187-204, 2012.

[60] E. Turban, D. Leidner, E. Mclean, and J. Wetherbe, Information Technology Management. Wiley India: New York, 2008.

[61] A. Vasileiadis, Security concerns and trust in the adoption of m-commerce, Social technologies, vol. 4, no. 1, pp. 179-191, 2014

[62] J. Veijalainen, V. Terziyan and H. Tirri, H. Transaction management for m-commerce at a mobile terminal, Electronic Commerce Research and Applications, vol. 5 no. 3, pp. 229-245, 2006.

[63] V. Venkatesh and H. Bala, Technology acceptance model 3 and a research agenda on interventions, Decision Sciences, vol. 39, no. 2, pp. 273-315, 2008.

[64] V. Vinzi, W. Chin and J. Henseler, Hand Book of Partial Least Squares. Germany: Springer, 2010.

[65] X. Wang, B. French and P. Clay, Convergent and discriminant validity with formative measurement: A mediator perspective, Journal of Modern Applied Statistical Methods, vol. 14, no. 1, pp. 83-106, 2015.

[66] C. Wong, G. Tan and K. Ooi, Mobile shopping: the next frontier of the shopping industry? An emerging market perspective, International Journal of Mobile Communication, vol. 13, no. 1, pp. 92-112, 2015.

[67] Wu and T. Hisa, Analysis of e-commerce innovation and impact: a hypercube model, Electronic Commerce Research and Applications, vol. 3, no. 4, pp. 389-404, 2004

[68] Y. Yang, Y. Liu, H. Li, and B. Yu, Understanding perceived risks in mobile payment acceptance, Industr Mngmnt \& Data Systems, vol. 115, no. 2, pp. 253-269, 2015.

[69] H. Yaseen, K. Dingley and C. Adams, Capturing the growth of e-commerce in Jordan using a novel research approach, International Journal of Management and Commerce Innovations, vol. 3, no. 2, pp. 811-827, 2015

[70] Zheng, M. Favier, P. Huang, and F. Coat, Chinese consumer perceived risk and risk relievers in e-shopping for clothing, Journal of Electronic Commerce Research, vol. 13 no. 3, pp. 255-274, 2012.

[71] Zheng, W. Tan, Y. Xu, and G. Tan, Dimensions of consumers' perceived risk and their influences on online consumers' purchasing behaviour', Communications in Information Science and Management Engineering, vol. 2, no. 7, pp. 8-14, 2012. 